\title{
Trabalho informal: uma revisão sistemática da literatura brasileira na área de Administração entre 2004 e 2013
}

\author{
THALES BATISTA DE LIMA \\ Universidade federal de Paraíba / Programa de Pós-Graduação em Administração, JoÃo Pessoa - PB, Brasil \\ MÁRCIA dA SILVA COSTA \\ Universidade federal de Paraíba / Programa de Pós-Graduação em Administração, João Pessoa - PB, Brasil
}

\begin{abstract}
Resumo
Este artigo analisa a literatura em administração sobre o trabalho informal, com base em artigos de eventos da Associação Nacional de PósGraduação e Pesquisa em Administração (Anpad) e dos principais periódicos nacionais em administração entre 2004 e 2013 . Aborda-se o trabalho informal no Brasil por meio de uma breve recuperação histórico-contextual para apresentar suas preocupações e desafios. Foi feita uma revisão sistemática da literatura brasileira, com base na análise de oito dimensões (abordagem metodológica, tipos de pesquisa, métodos de coleta e análise dos dados, autores que mais produzem na área, referências mais usadas, área de formação dos autores e assuntos mais explorados), cujos resultados explicitam o quanto esse assunto ainda é incipiente na produção acadêmica nacional em administração. Portanto, é necessária maior atenção para o tema do trabalho informal, visto ser uma realidade no meio social, sobre a qual o campo organizacional tem responsabilidade.
\end{abstract}

Palavras-chave: Trabalho informal. Literatura em administração. Revisão sistemática da literatura.

\section{Informal labor: a systematic review of Brazilian literature on Administration between 2004 and 2013}

\begin{abstract}
This article analyzes the administration literature on informal employment, based on articles from events of the Brazilian National Association of Graduate Studies and Research in Administration (Anpad) and the main Brazilian journals in administration between 2004 and 2013 . It addresses informal employment in Brazil by means of a brief historical and contextual review to introduce the concerns and challenges. A systematic review of the Brazilian literature was conducted, having as a basis the analysis of eight dimensions (methodological approach, research types, data collection and analysis methods, most prolific authors in the field, most frequently used references, authors' undergraduate degree, and most frequently addressed subjects), whose results highlight how this issue still remains incipient in the Brazilian academic literature in administration. Therefore, greater attention is needed on the theme of informal employment, as this is a reality in the social environment, over which the organizational field is accountable.
\end{abstract}

Keywords: Informal employment. Administration literature. Systematic literature review.

\section{Trabajo informal: una revisión sistemática de la literatura brasileña en el área de Administración entre 2004 y 2013}

\section{Resumen}

Este artículo analiza la literatura en administración con relación al trabajo informal, basado en artículos de eventos de la Asociación Nacional de Pos Grado e Investigación en Administración (Anpad) y de los principales periódicos nacionales en administración entre 2004 y 2013. Abordase el trabajo informal en Brasil por medio de una breve recuperación histórica contextual para presentar sus preocupaciones y desafíos. Fue hecha una revisión sistemática de la literatura brasileña, con base en el análisis de ocho dimensiones (abordaje metodológico, tipos de investigación, métodos de recolección y análisis de datos, autores que más producen en el área, referencias más utilizadas, área de formación de los autores y temáticas más explotadas) cuyos resultados explican lo cuanto esa temática hasta entonces se presenta de forma rudimentaria en la producción académica nacional en administración. Por lo tanto, es necesaria una mayor atención para el tema del trabajo informal, visto ser una realidad en el medio social, sobre la cual el campo organizativo tiene responsabilidad.

Palabras clave: Trabajo informal. Literatura en administración. Revisión sistemática de la literatura. 


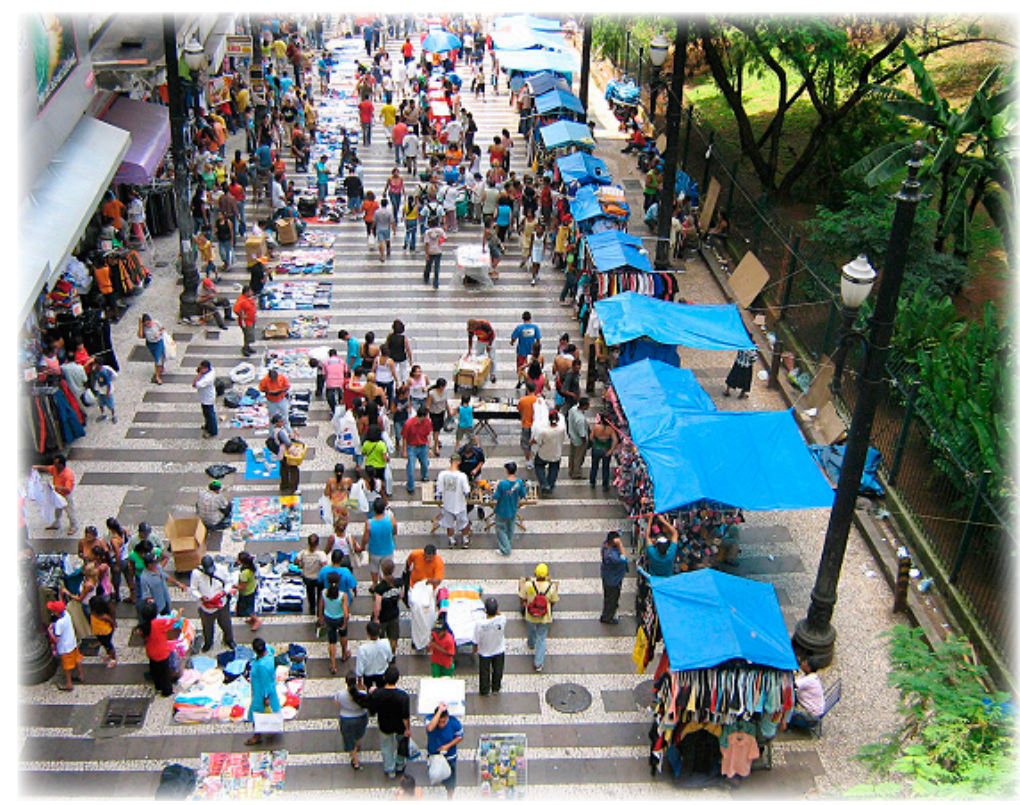

\section{INTRODUÇÃO}

O aumento do trabalho informal no país tem sido um desafio para governos interessados em fomentar políticas públicas que intensifiquem a oportunidade de emprego formal, ainda mais com qualidade, ou seja, com condições satisfatórias de bem-estar oferecidas aos trabalhadores, de forma a propiciar-lhes dignidade.

Soares (2008) tem trabalhado a ideia de que, com a crise do capitalismo na década de 1970, e a consequente dificuldade para a retomada do aumento da taxa de lucro, emerge um novo modo de acumulação, conhecido como acumulação flexível. Abonizio (2010) chama a atenção para as novas formas de trabalho que surgem ou são reincorporadas.

A década de 1970 foi marcada pela eclosão de interpretações críticas sobre o desenvolvimento da produção e suas inter-relações com o mercado de trabalho (CACCIAMALI, 1983; LEITE, 2011). A partir daí, os arranjos informais de emprego se ampliaram e se diversificaram com as experiências de desverticalização e enxugamento da típica organização fordista do trabalho mediante iniciativas diversas de subcontratação e demissões em massa nas grandes organizações (COSTA, 2010a).

De acordo com Oliveira (2005), o trabalho informal, ampliado drasticamente entre meados dos anos 1980 e toda a década de 1990, foi a alternativa de sobrevivência diante da incapacidade do sistema capitalista de absorver a mão de obra ativa existente e da falta de políticas públicas capazes de inserir os trabalhadores no mercado formal.

No Brasil, que historicamente construiu um regime de trabalho parco em direitos, as dificuldades foram ainda maiores, sobretudo na década de 1990, com as iniciativas neoliberais de ajuste econômico e de introdução no mercado global. Não houve avanços significativos na regulamentação do trabalho, visto que os interesses preponderantes da burguesia monopolista não visaram a distribuir mais equitativamente a renda, ou seja, o desenvolvimento econômico do país não foi acompanhado do desenvolvimento social, o que pôde ser sentido diretamente pela elevação da precariedade do trabalho, levando muitos trabalhadores à informalidade (LIMA, CAVALCANTE e COSTA, 2011).

Todavia, Leite (2011) afirma que, nos anos 2000, o país conseguiu recuperar o processo de reestruturação do mercado de trabalho, dada a retomada da formalização do trabalho por meio do aumento do emprego formal e da recuperação do poder

\footnotetext{
* Fonte da imagem: Marcos Santos/USP Imagens. Disponível em <http://www.imagens.usp.br/wp-content/uploads/trab_informal0032.jpg>. Acesso em 14 mar. 2016.
} 
de compra dos salários. Entretanto, continuou a conviver com a tendência à precarização das formas de trabalho, que, assim, domina esse panorama como um processo duplo que ocorre simultaneamente no mercado de trabalho brasileiro.

Sendo assim, o tema é oportuno, pois permite o debate sobre as alternativas possíveis para contornar essa preocupante situação, sobretudo em um país que registra vertiginoso crescimento da informalidade e cujo Estado parece não tomar decisões cabíveis para aprimorar formas de trabalho precárias, reflexo de um sistema capitalista que idealizava a igualdade entre as pessoas baseada em relações de trabalho dignas, o que não aconteceu.

Salienta-se que não é só fomentando o crescimento econômico no país que se garantem mais empregos formais, bem como distribuição de renda equitativa. É preciso reconfigurar as formas de trabalho diante da precarização que houve no decorrer das últimas décadas, culminando na escolha da informalidade como meio de vida alternativo para a sobrevivência de muitas pessoas. Como afirma Costa (2010a, p. 187), "a informalidade é um problema social, portanto, de interesse público".

Para ter uma ideia melhor do panorama, apresentam-se algumas informações colhidas na última versão elaborada pelo Instituto Brasileiro de Geografia e Estatística (IBGE) do Projeto Economia Informal Urbana (2003), em que se verifica que grande parte das empresas do setor informal pertencia aos trabalhadores autônomos (88\%) em 2003, sendo apenas $12 \%$ de pequenos empregadores. As atividades econômicas preponderantes nesse setor eram comércio e reparação (33\%), construção civil (17\%) e indústria de transformação e extrativa (16\%).

A atividade produtiva era desenvolvida fora do domicílio em $65 \%$ dos casos, exclusivamente no domicílio do proprietário em $27 \%$, e no domicílio do proprietário e fora dele em $8 \%$ dos casos, resultado influenciado pelo peso de atividades como comércio e construção civil. As unidades produtivas que informaram o valor de sua receita mensal, em média, faturavam mais em 1997 do que em 2003. Parcela significativa das empresas de conta própria (22\%) recebeu, em média, entre $R \$ 501,00$ e $R \$$ $1.000,00$. As empresas de empregadores, por sua vez, alcançaram maior faturamento: $63 \%$ com receita mensal superior a $R \$$ $2.000,00$. Cabe destacar ainda que a receita média obtida pelas empresas de empregadores $(R \$ 6.033,00)$ era cerca de cinco vezes superior àquela obtida pelas empresas de conta própria $(R \$ 1.164,00)$.

Entre as empresas do setor informal, $88 \%$ não estavam constituídas juridicamente, correspondendo a $93 \%$ das empresas de conta própria e $56 \%$ das de empregadores. Quanto às características das pessoas ocupadas nas empresas do setor informal, tem-se a seguinte conjuntura: $69 \%$ eram trabalhadores por conta própria, 10\% empregadores, $10 \%$ empregados sem carteira assinada, $6 \%$ trabalhadores com carteira assinada e 5\% não remunerados. Essas proporções pouco se alteraram em relação a 1997, quando $67 \%$ eram trabalhadores por conta própria, $12 \%$ empregadores, $10 \%$ empregados sem carteira assinada, $7 \%$ trabalhadores com carteira assinada e $4 \%$ não remunerados.

Já em relação às características dos proprietários de empresas do setor informal, os dados mostram que 66\% eram homens, entre os quais $95 \%$ não tinham sócios, e grande parcela já era proprietário há mais de dez anos (30\%), diminuindo, inclusive, a proporção de proprietários que estava há menos de um ano no negócio entre 1997 (18\%) e 2003 (12\%). Por sua vez, dos proprietários de empresas do setor informal há menos de cinco anos, que representam $26 \%$ do total de proprietários, a maioria já havia trabalhado anteriormente no setor formal. No entanto, o principal motivo informado para a saída do último emprego era distinto segundo o sexo. Para os homens, foi o fato de terem sido dispensados (33\%) e, para as mulheres, foram motivos pessoais ou familiares (28\%).

Diante desse cenário, percebe-se o quão necessário é pensar em como lidar com o trabalho informal. Apesar de o Estado exercer um papel preponderante diante dessa situação, também cabe à iniciativa privada refletir sobre suas ações, tratadas, em especial, pela área de recursos humanos, responsável pelas relações de trabalho oferecidas.

Sendo assim, é interessante observar os estudos existentes sobre esse tema no campo da administração, pois este também tem um papel importante no fomento de pesquisas científicas que elucidem o devido tratamento a ser dado à informalidade, uma vez que os cursos de administração pouco incentivam estudos críticos que ferem a lógica capitalista de produtivismo exacerbado para a obtenção imediata de lucro, na qual se sobressai socialmente aquele que acumula maior renda. Com base nesse entendimento, destaca-se o questionamento de Ferraz e Menna-Barreto $(2010$, p. 2) sobre o quanto a administração carece de melhor compreensão sobre o tema. 


\begin{abstract}
A Administração é uma área do conhecimento que busca, primordialmente, planejar, avaliar e aprimorar técnicas que visem o aumento da produtividade do trabalho, têm-se, portanto, essa ciência colaborando para o fenômeno do desemprego estrutural e impulsionando a informalidade. Estudos administrativos acerca do primeiro são raros; sobre o segundo, há alguns esforços para compreendê-lo, mas por via de regra, partem de abordagem que vislumbram os trabalhadores desempregados que atuam na "economia informal" ora como empreendedores ora como público alvo de projetos políticos sociais, tais como a economia solidária ou os programas de responsabilidade empresarial corporativa, por considerar que estes trabalhadores são pessoas excluídas.
\end{abstract}

Por isso, este trabalho objetiva desenvolver uma análise da produção científica em administração sobre o trabalho informal, com base nos artigos de eventos da Associação Nacional de Pós-Graduação e Pesquisa em Administração (Anpad) e dos principais periódicos nacionais de administração no período 2004 a 2013.

Inicialmente, foi feito um levantamento dos trabalhos sobre o tema nas publicações já citadas, que foram concomitantemente mapeados. A análise detalha o número de artigos produzidos nos eventos e publicados em periódicos selecionados nos últimos dez anos, bem como dos temas propostos pelos artigos sobre trabalho informal, indicando-se os autores, as referências mais citadas e os procedimentos metodológicos adotados, entre outros aspectos considerados relevantes para uma análise consistente da produção científica sobre esse assunto.

O artigo está estruturado em cinco tópicos: a Introdução explicita o objetivo do trabalho; a Fundamentação Teórica aborda o trabalho informal no Brasil; a Metodologia apresenta como foi feita a Revisão Sistemática da Literatura (RSL), o processo de coleta e a análise dos dados; a Análise dos Resultados abarca a discussão de oito dimensões; e, por fim, há as Considerações Finais.

\title{
O TRABALHO INFORMAL NO BRASIL
}

A informalidade, por vezes, é difícil de ser tratada em razão de sua definição vasta e imprecisa. Segundo Cacciamali (1983), a definição para caracterizar o setor, o mercado e/ou o trabalho informal dá margem a ângulos interpretativos diversos, pois cada uma das suas condições não se dá, em geral, com a mesma intensidade, nem simultaneamente. Para a autora, o trabaIho informal é considerado o trabalho autônomo que persiste até a atualidade no interior da produção capitalista.

Outros autores encaram o trabalho informal de modo mais amplo, como Abonizio (2010) e Mészáros (2006), para os quais a crise do desemprego vivida pela sociedade capitalista não se restringe às economias menos avançadas e aos trabalhadores menos qualificados; pelo contrário, essa situação abrange tanto os países avançados quanto a totalidade da força de trabaIho. Portanto, o discurso hegemônico que vincula os trabalhadores informais ao patamar de autônomos, independentes ou empreendedores torna-se inócuo em face da objetiva estrutura social.

Enfim, o trabalho informal como referência a um modo específico de participar do mercado de trabalho é uma invenção moderna que ainda não encontrou uma conceituação consensual entre os estudiosos do tema (SASAKI, 2009). Segundo esse autor, a noção de um setor formal, no sentido de estruturado e regulado, surgiu com o advento do modo capitalista de produção e com a constituição de um ente abstrato - o mercado de trabalho - em que o recrutamento de trabalhadores passou a ser institucionalizado na forma de emprego, como produto ou mercadoria a ser comercializada. Para ele, o modelo de um mercado regulado implica o contraponto de atividades não reguladas ou não cobertas por normas que regem esse mercado. As denominações das atividades não reguladas variam conforme o enfoque teórico dos estudos: setor não protegido, setor informal, processo de informalidade. Assim, a institucionalização dos termos formal-informal parece indicar uma classificação em situações reguladas e não reguladas de trabalho. Nesse sentido, explica-se o modo informal de trabalho pela oposição ao modo formal de trabalhar.

Esse foco nas questões de regulação como modo de conceituação de trabalho formal e informal é fortemente acentuado na década de 1970 com a crise do modelo fordista dominante. Antunes (2000) comenta que os sinais dessa crise foram: a redução da taxa de lucro motivada, entre outros, pelo aumento do preço da força de trabalho e pelas lutas sociais ocorridas nos anos 1960; a incapacidade do modelo em se adaptar à retração de consumo gerada pelo desemprego estrutural que então 
começa a se manifestar; o aumento da esfera financeira, que inicia um processo de autonomização diante dos capitais produtivos, tornando-se o campo prioritário para a especulação; a concentração do capital gerada pelas fusões de empresas; e a crise do Estado de Bem-Estar Social, levando à retração dos gastos públicos.

Tal crise foi abalada pelas pressões da competitividade internacional, na qual se introduziu a ideologia neoliberal que postulava a redução do papel do Estado na economia e a desregulamentação dos mercados de trabalho (COSTA, 2010b). No Brasil, esse mercado de trabalho se origina já de modo segmentado, visto que, o marco legal da Consolidação das Leis do Trabalho (CLT), como alega essa autora, incorporava os trabalhadores de maneira bastante limitada mediante duas frentes: primeiro, porque a legislação de direitos mínimos e de sindicalização deixava de fora a grande massa dos trabalhadores rurais, na época maioria absoluta da força de trabalho, e os servidores públicos; segundo, porque grande parcela dos trabalhadores urbanos não gozou do status do emprego regulamentado e sobre o qual o Estado definia as políticas de seguridade social.

Portanto, o Brasil não concretizou o projeto fordista de regulação social. Muito da organização técnica do trabalho foi introduzida e apropriada, mas os arranjos políticos da negociação coletiva e da conciliação de interesses não foram implementados em boa parte da trajetória do desenvolvimento industrial/capitalista. Ainda que o governo Vargas, nos anos 1940, tivesse instituído uma regulação para o emprego no país, observou-se posteriormente que os direitos que não abrangeram os trabalhadores rurais e muitos trabalhadores urbanos, parte do contingente dos empregados em atividades informais (LIMA, CAVALCANTE e COSTA, 2011).

Costa (2006) chama a atenção para o fato de que, mesmo com o crescimento econômico ocorrido no período da crise na década de 1970, em que se dá o chamado "milagre econômico", o Estado não conseguiu reduzir o trabalho informal uma vez que esse crescimento se deu sem redistribuição de renda e sem redução das históricas desigualdades sociais, acentuando a desestruturação do mercado de trabalho e marcando sua heterogeneidade. Para Oliveira (2005), a informalidade, as atividades subterrâneas (sem identificação ou legitimação social) e de sobrevivência alimentavam o mercado formal, ou seja, a economia capitalista regulada, de mão de obra barata e disciplinada, gerando uma simbiose entre a relação informal e formal.

Segundo Lima, Cavalcante e Costa (2011) e Oliveira (2005), essa dinâmica formal/informal da economia brasileira, que embute fortes relações de dominação, foi responsável pela reprodução do nível de pobreza da população, do subemprego, dos desequilíbrios regionais, dos níveis de desigualdade social, da exclusão e da concentração de renda. De fato, no Brasil, grande parte da informalidade provém de um contingente majoritário de trabalhadores oriundos de grupos sociais pauperizados, sobretudo por conta da ausência de qualificação e recursos, e que se insere em condições de trabalho das mais precárias (COSTA, 2010a; SILVA, 2003).

Assim, percebe-se que o processo de coesão social necessário para dar conta das desigualdades, emergido a partir da década de 1980, não poderia ser entregue apenas à iniciativa privada, uma vez que esta atua na lógica do mercado, em que impera a competitividade e o individualismo. Dessa forma, é papel do Estado garantir o interesse coletivo e o bem-estar social. Mattoso (1997) argumenta que, no caso brasileiro, sua adequação subordinada às condições da nova ordem ditada pelos agentes financeiros internacionais acelerou o processo de desestruturação e de redução de sua capacidade de planejamento, financiamento, fiscalização, apoio à competitividade e à distribuição de renda.

Nesse sentido, boa parte do crescimento da informalidade e da precariedade do trabalho na década de 1990 pode ser explicada pela redução e evasão, por parte das empresas, do cumprimento de seus encargos trabalhistas e sociais. E isso, no Brasil, em muito se deve aos baixos custos da ilegalidade (COSTA, 2010a; BARBOSA, 2011; LEITE, 2011). Ou seja, as recentes estratégias de acumulação de capital se beneficiam também da tolerância e da falta de controle do Estado para expandir e recriar diversas modalidades de operação não regularizada de suas atividades. Tal fenômeno reitera a tendência secular de burla ao ordenamento jurídico, prejudicial não apenas aos trabalhadores informais, mas a todo o conjunto da sociedade, posto que o Estado tem não só sua base tributária reduzida, mas também sua própria capacidade de regulamentar a economia (DIEESE, 1997; SILVA, 2003; COSTA, 2010a;).

Logo, o processo de reestruturação produtiva por meio das novas tecnologias físicas de base microeletrônica e de novas formas de organização e gestão do trabalho promove a implementação de uma nova base técnica que é poupadora de mão de obra, levando ao crescimento do desemprego estrutural (KREMER e FARIA, 2005), e, consequentemente, elevando o número de trabalhadores informais. 
Sendo assim, o trabalho informal é, atualmente, um dos problemas centrais da sociedade brasileira e, para Costa (2010b), está no âmago das profundas desigualdades estruturais, marca de um padrão de acumulação concentrador de renda e perpetuador de uma pobreza sem precedentes. Por isso, é necessário compreender melhor esse fenômeno à luz de argumentos teóricos que propiciem contribuições à sociedade no sentido de delinear um caminho diante do trabalho informal.

Contudo, as pesquisas sobre o tema ainda parecem esparsas, trazendo à tona os dilemas do trabalho informal, em geral em uma perspectiva histórica, recuperando o papel do Estado como alternativa viável para sanar esse problema mediante regulação das novas formas de trabalho. A necessidade de conhecimento sobre o tema é bem mais profunda, como pôde ser visto anteriormente, já que, segundo Barbosa (2011), ele é indefinido e atua em um ambiente complexo.

Portanto, é preciso que haja mais pesquisadores envolvidos com esse tema para desenvolver estudos que possam contribuir significativamente com a área, até mesmo auxiliando o Estado em seu posicionamento e em suas medidas para melhorar a situação. Isso pode ser observado pela análise desenvolvida a seguir a respeito da produção acadêmica em administração sobre tal assunto.

\section{METODOLOGIA}

Este estudo objetiva identificar como o trabalho informal foi abordado pela produção científica de artigos no Brasil na área da administração, no período de 2004 a 2013. A metodologia adotada foi a Revisão Sistemática da Literatura (RSL) mediante o levantamento dos artigos publicados nos eventos vinculados à Anapd e nos principais periódicos em administração, conforme o entendimento dos autores Delfino, Silva e Rohde (2010). A RSL é uma forma de agregar conhecimento e reunir saberes sobre um tema, facilitando o trabalho dos pesquisadores. Requer um extenso esforço de classificação e encontro de trabalhos relevantes, o que demanda um tempo considerável (KITCHENHAM, PRETORIUS, BUDGEN et al., 2010).

Foram analisados artigos publicados nos três eventos da Anpad, com enfoque em relações de trabalho, nos últimos dez anos. Os eventos foram o Encontro Nacional da Anpad (EnANPAD), o Encontro de Estudos Organizacionais (EnEO) e o Encontro de Gestão de Pessoas e Relações de Trabalho (EnGPR). O EnANPAD é anual e o EnEO e o EnGPR são bienais. No período analisado por este estudo, que ocorreu em abril do ano de 2014, registraram-se edições do EnEO de 2004 a 2012 e do EnGPR entre 2007 e 2013.

Para a busca foram considerados os artigos que tratavam diretamente do tema trabalho informal, com as palavras-chave setor/mercado/trabalho informal e informalidade. A pesquisa foi conduzida no site da Anpad e nos CDs dos eventos. Foram localizados apenas três artigos, cada um deles correspondente a um evento. A seguir, apresentam-se os artigos encontrados de acordo com os eventos.

Tabela 1

Eventos e número de artigos sobre o tema publicados por ano

\begin{tabular}{|c|c|c|c|c|c|c|c|c|c|c|c|}
\hline \multirow{2}{*}{ Eventos/ano } & \multicolumn{11}{|c|}{ Número de artigos } \\
\hline & 2004 & 2005 & 2006 & 2007 & 2008 & 2009 & 2010 & 2011 & 2012 & 2013 & TOTAL \\
\hline ENANPAD & & & & & & & & 1 & & & 1 \\
\hline ENEO & & & & & & & 1 & & & & 1 \\
\hline ENGPR & & & & & & & & 1 & & & 1 \\
\hline TOTAL & 0 & 0 & 0 & 0 & 0 & 0 & 1 & 2 & 0 & 0 & 3 \\
\hline
\end{tabular}

Fonte: Elaborada pelos autores.

Para aprofundar o estudo, também foram analisados os artigos publicados em periódicos nacionais de administração avaliados no sistema Qualis da Coordenação de Aperfeiçoamento e Capacitação de Pessoal de Nível Superior (Capes) em estratos que variam de $\mathrm{A} 1$ até B3, classificações consideradas de maior impacto no meio acadêmico. Contudo, vale salientar que no extrato A1 não foram encontrados artigos sobre o tema. Por isso, foram selecionados os seguintes periódicos: Revista de 
Administração Contemporânea (RAC); Revista de Administração de Empresas (RAE); Organização e Sociedade (O\&S); Brazilian Administration Review (BAR); Revista de Administração Pública (RAP); Revista de Administração Mackenzie (RAM); Cadernos EBAPE.BR; Revista de Administração da Universidade de São Paulo (RAUSP); Revista de Ciências da Administração (RCA); Revista Gestão Organizacional (RGO); BASE Unisinos; Revista Eletrônica de Administração (REAd); Administração: Ensino e Pesquisa (RAEP); Revista Gestão e Sociedade (RGES). O Quadro 1 apresenta os periódicos e o respectivo extrato.

\section{Quadro 1}

\section{Periódico e extrato}

\begin{tabular}{|c|c|}
\hline Periódico & Extrato \\
\hline RAC & A2 \\
\hline RAE & A2 \\
\hline O\&S & A2 \\
\hline BAR & A2 \\
\hline RAP & A2 \\
\hline RAUSP & A2 \\
\hline Cadernos EBAPE.BR & B1 \\
\hline RAM & B1 \\
\hline BASE Unisinos & B1 \\
\hline RCA & B1 \\
\hline READ & B1 \\
\hline RGO & B2 \\
\hline RAEP & B3 \\
\hline RGES & B3 \\
\hline
\end{tabular}

Fonte: Elaborada pelos autores.

A busca feita nesses catorze periódicos encontrou apenas cinco artigos sobre trabalho informal, o que evidencia a incipiência do assunto nas pesquisas acadêmicas em administração. A Tabela 2 descreve os periódicos em relação ao ano de publicação dos artigos.

Tabela 2

Periódicos e quantidade de artigos sobre o tema publicados por ano

\begin{tabular}{|c|c|c|c|c|c|c|c|c|c|c|c|}
\hline \multirow{2}{*}{ Periódicos/ano } & \multicolumn{11}{|c|}{ Número de artigos } \\
\hline & 2004 & 2005 & 2006 & 2007 & 2008 & 2009 & 2010 & 2011 & 2012 & 2013 & TOTAL \\
\hline RAC & & & & & & & & & & & 0 \\
\hline RAE & & & & & & & & & & & 0 \\
\hline O\&S & & & & & & & & & & & 0 \\
\hline BAR & & & & & & & & & & & 0 \\
\hline RAP & & & & & & 1 & & & & & 1 \\
\hline RAM & & & & & & & & & & & 0 \\
\hline Cadernos EBAPE.BR & & & & & 1 & & & & & & 1 \\
\hline RAUSP & & 1 & & & & & & & & & 1 \\
\hline RCA & & & & & & & & & & & 0 \\
\hline RGO & & & & & & 1 & & & & & 1 \\
\hline BASE Unisinos & & & & & & & & & & & 0 \\
\hline READ & & & & & & & & & & & 0 \\
\hline RAEP & & & & & & & & & & & 0 \\
\hline RGES & & & & & & & & & & 1 & 1 \\
\hline TOTAL & 0 & 1 & 0 & 0 & 1 & 2 & 0 & 0 & 0 & 1 & 5 \\
\hline
\end{tabular}

Fonte: Elaborada pelos autores. 
Percebe-se que, se considerarmos o número de artigos sobre o tema, identificamos, de imediato, o baixo número de artigos, tanto em eventos quanto em periódicos, que tratam do trabalho informal. Vale a pena analisar se os artigos existentes demonstram o rigor e a relevância necessários da pesquisa científica sobre o tema em estudo e identificar o enfoque que Ihe foi dado por seus autores. Para tanto, foram considerados os artigos que abordam diretamente o trabalho informal. Ou seja, no processo de busca foram excluídos os artigos que só citavam o trabalho informal como um elemento apurado nos resultados finais de outro assunto, por exemplo: tratar das relações de trabalho em geral e, no final da análise, considerar que a informalidade é um dos elementos que necessitam de atenção. Nesses casos, o tema não foi aprofundado, até porque a ênfase do artigo não era o trabalho informal.

Os artigos foram separados por ano do evento realizado ou por ano de publicação no periódico. Ao mesmo tempo, já se identificavam os objetivos, sendo eliminados os que não correspondiam ao objetivo proposto por este trabalho. Depois desse processo de coleta dos artigos, foram elaborados os aspectos a ser analisados a fim de entender melhor como vêm sendo tratados os estudos sobre trabalho informal.

Para tanto, buscou-se identificar a abordagem metodológica adotada pelos artigos, tipos de pesquisa, os métodos de coleta e de análise dos dados, os autores que mais produzem na área, as referências mais indicadas, com base na observação das referências indicadas no fim desses artigos, a área de formação dos autores à época em que os artigos foram publicados e os assuntos mais explorados apontados pelos autores.

\section{ANÁLISE DOS RESULTADOS}

Em relação à parte metodológica dos artigos selecionados, foram analisados quanto à sua abordagem, em que se nota uma diferença significativa entre o número de estudos que adotaram a abordagem quantitativa e a qualitativa.

Destaca-se que, dentre os artigos apresentados nos eventos, há um ensaio teórico e dois artigos, ambos de 2011, um com abordagem quantitativa e outro com qualitativa. Já nos artigos dos periódicos houve também um ensaio teórico, em 2005, sendo os demais qualitativos. Os artigos dos eventos foram equilibrados em termos de abordagem metodológica; já a maioria dos artigos de periódicos é qualitativa. É interessante observar que os estudos ainda não exploram a forma mista (quanti-quali ou quali-quanti).

\section{Tabela 3}

\section{Abordagem dos artigos}

\begin{tabular}{|c|c|c|c|c|c|c|c|c|c|c|c|c|}
\hline Artigos & Abordagem & 2004 & 2005 & 2006 & 2007 & 2008 & 2009 & 2010 & 2011 & 2012 & 2013 & TOTAL \\
\hline \multirow{3}{*}{$\begin{array}{c}\text { ENANPAD/ } \\
\text { ENEO/ ENGPR }\end{array}$} & Ensaio teórico & & & & & & & 1 & & & & 1 \\
\cline { 2 - 13 } & Quantitativa & & & & & & & & 1 & & & 1 \\
\hline & Qualitativa & & & & & & & & 1 & & & 1 \\
\hline & Mista & & & & & & & & & & & 0 \\
\hline \multirow{4}{*}{ PERIÓdICOS } & Ensaio teórico & & 1 & & & & & & & & & 1 \\
\hline & Quantitativa & & & & & & & & & & & 0 \\
\hline & Qualitativa & & & & & 1 & 2 & & & & 1 & 4 \\
\hline
\end{tabular}

Fonte: Elaborada pelos autores.

Nas tabelas a seguir são listados apenas os anos em que há publicação de artigos nos eventos e periódicos, para melhor visualização. Não houve nenhuma publicação nos eventos e periódicos selecionados referentes aos anos de 2004, 2006, 2007 e 2012.

Sendo assim, em relação ao tipo de pesquisa, pôde-se observar que a maioria dos artigos provenientes dos eventos é do tipo descritivo e a maioria dos advindos dos periódicos não identifica o tipo de pesquisa, o que prejudica o rigor metodológico de 
tais artigos. Não houve nenhum artigo que se valesse mais de um tipo de pesquisa e também que fosse explicativa. $O$ único artigo quantitativo usou o tipo descritivo.

Tabela 4

Tipo de pesquisa dos artigos

\begin{tabular}{|c|c|c|c|c|c|c|c|c|}
\hline Artigos & TIPO DE PESQUISA & 2005 & 2008 & 2009 & 2010 & 2011 & 2013 & TOTAL \\
\hline \multirow{5}{*}{ ENANPAD/ENEO/ENGPR } & Descritiva & & & & 1 & 1 & & 2 \\
\hline & Exploratória & & & & & & & 0 \\
\hline & Explicativa & & & & & & & 0 \\
\hline & Mais de um tipo & & & & & & & 0 \\
\hline & Não identificado & & & & & 1 & & 1 \\
\hline \multirow{5}{*}{ PERIÓDICOS } & Descritiva & 1 & & & & & & 1 \\
\hline & Exploratória & & & 1 & & & & 1 \\
\hline & Explicativa & & & & & & & 0 \\
\hline & Mais de um tipo & & & & & & & 0 \\
\hline & Não identificado & & 1 & 1 & & & 1 & 3 \\
\hline \multicolumn{2}{|c|}{ TOTAL } & 1 & 1 & 2 & 1 & 2 & 1 & 8 \\
\hline
\end{tabular}

Fonte: Elaborada pelos autores.

Em relação à técnica de coleta de dados, percebeu-se que os artigos selecionados trabalham mais com a técnica da entrevista, já que a maioria é composta por estudos qualitativos. Nos artigos dos eventos, um usou o questionário e, no de 2010, um ensaio teórico, não foi possível identificar a coleta. Mais uma vez, nenhum artigo adota a forma mista e um dos artigos de periódico do ano 2009 usa a entrevista associada à técnica de discurso da mídia impressa e à pesquisa documental. Quando a entrevista não pôde ser feita com os sujeitos estudados, os autores elaboraram um questionário e se pautaram também na observação.

Tabela 5

Técnica de coleta de dados dos artigos

\begin{tabular}{|c|c|c|c|c|c|c|c|c|}
\hline Artigos & $\begin{array}{c}\text { Técnica de coleta de } \\
\text { dados }\end{array}$ & 2005 & 2008 & 2009 & 2010 & 2011 & 2013 & TOTAL \\
\hline \multirow{8}{*}{ ENANPAD/ ENEO/ ENGPR } & Questionário & & & & & 1 & & 1 \\
\hline & Entrevista & & & & & 1 & & 1 \\
\hline & Análise bibliográfica & & & & & & & 0 \\
\hline & Diário de campo & & & & & & & 0 \\
\hline & Análise documental & & & & & & & 0 \\
\hline & Mais de uma técnica & & & & & & & 0 \\
\hline & Outra técnica & & & & & & & 0 \\
\hline & Não identificado & & & & 1 & & & 1 \\
\hline \multirow{8}{*}{ PERIÓDICOS } & Questionário & & & & & & & 0 \\
\hline & Entrevista & & 1 & 1 & & & 1 & 3 \\
\hline & Análise bibliográfica & & & & & & & 0 \\
\hline & Diário de campo & & & & & & & 0 \\
\hline & Análise documental & & & & & & & 0 \\
\hline & Mais de uma técnica & & & 1 & & & & 1 \\
\hline & Outra técnica & & & & & & & 0 \\
\hline & Não identificado & 1 & & & & & & 1 \\
\hline \multicolumn{2}{|c|}{ TOTAL } & 1 & 1 & 2 & 1 & 2 & 1 & 8 \\
\hline
\end{tabular}

Fonte: Elaborada pelos autores. 
No que diz respeito ao método de análise dos dados, 5 artigos adotaram a análise do discurso ou conteúdo. É interessante esclarecer que tais artigos balizam seus argumentos em diferentes autores para fundamentar sua análise de discurso/conteúdo. $O$ artigo que apresenta mais de uma técnica de coleta diz que adota a análise crítica do discurso. Já o artigo cuja abordagem é quantitativa analisou seus dados mediante a correlação e a regressão. E dois artigos, um de evento e um de periódico, que não identificaram sua análise, trabalharam na perspectiva do ensaio teórico.

Entretanto, a não identificação do tipo de pesquisa, bem como da técnica de coleta e do método de análise, indica maior necessidade de cuidado dos autores em relação à visibilidade de suas técnicas de coleta e métodos de análise em suas pesquisas. Também consideramos pertinente refletir sobre os critérios de avaliação dos eventos e dos periódicos, que ainda parecem ser deficientes em alguns aspectos, como o rigor, a clareza e a coesão dos procedimentos metodológicos.

\section{Tabela 6}

Método de análise de dados dos artigos

\begin{tabular}{|c|c|c|c|c|c|c|c|c|}
\hline Artigos & Método de análise & 2005 & 2008 & 2009 & 2010 & 2011 & 2013 & TOTAL \\
\hline \multirow{10}{*}{ ENANPAD/ENEO/ENGPR } & Estatística descritiva & & & & & & & 0 \\
\hline & Correlação/Regressão & & & & & 1 & & 1 \\
\hline & Multivariada & & & & & & & 0 \\
\hline & Análise do Discurso/Conteúdo & & & & & 1 & & 1 \\
\hline & História oral & & & & & & & 0 \\
\hline & Etnografia & & & & & & & 0 \\
\hline & Análise de narrativa & & & & & & & 0 \\
\hline & Mais de uma análise & & & & & & & 0 \\
\hline & Outra análise & & & & & & & 0 \\
\hline & Não identificado & & & & 1 & & & 1 \\
\hline \multirow{10}{*}{ Periódicos } & Estatística descritiva & & & & & & & 0 \\
\hline & Correlação/Regressão & & & & & & & 0 \\
\hline & Multivariada & & & & & & & 0 \\
\hline & Análise do Discurso/Conteúdo & & 1 & 2 & & & 1 & 4 \\
\hline & História oral & & & & & & & 0 \\
\hline & Etnografia & & & & & & & 0 \\
\hline & Análise de narrativa & & & & & & & 0 \\
\hline & Mais de uma análise & & & & & & & 0 \\
\hline & Outra análise & & & & & & & 0 \\
\hline & Não identificado & 1 & & & & & & 1 \\
\hline \multicolumn{2}{|c|}{ TOTAL } & 1 & 1 & 2 & 1 & 2 & 1 & 8 \\
\hline
\end{tabular}

Fonte: Elaborada pelos autores.

Em relação aos autores que mais produzem nessa área, percebeu-se, surpreendentemente, que a maioria aborda pontualmente o assunto, ou seja, não há autores que trabalham preponderantemente com o tema do trabalho informal. Eles praticamente só apresentaram um artigo nesses dez anos nos eventos e periódicos pesquisados.

Na Tabela 7, pode se observar que apenas três autores estão presentes, em coautoria, em três produções distintas de periódicos. Salienta-se que, na publicação do Cadernos EBAPE.BR, contaram com a parceria de Milena Cristiane Nascimento Mendonça e de Alfredo Rodrigues Leite da Silva, ao passo que no periódico RGO contaram com a colaboração de Mariana Mayumi Pereira de Souza.

É interessante observar que os autores dos artigos direcionados aos eventos da Anpad em nenhum momento aparecem em produções de periódicos, o que demonstra que não têm como foco o trabalho informal em suas publicações. É possível arriscar que também a parca produção do tema em administração seja decorrência da falta de grupos de pesquisa voltados para assuntos tidos como pertencentes à zona de fronteira nas subáreas relações de trabalho e recursos humanos, mesmo havendo já eventos da própria Anpad com tal ênfase. Aliás, percebe-se o quanto na formação em administração prevalece o 
posicionamento funcionalista, o que acarreta a baixa produção de temas candentes para a sociedade que digam respeito ao campo da organização como exercício de sua função social.

Destaca-se, também, que provavelmente os referidos autores pesquisados e até mesmo outros pesquisadores em administração publiquem em outros eventos e periódicos, não pertencentes ao campo da administração, em virtude da visão ainda míope desse campo sobre o assunto. Além disso, tal tema acaba sendo mais explorado em outras áreas do conhecimento, como a sociologia.

Dessa forma, verifica-se que não há tantos pesquisadores da área de administração cujas publicações enfatizem esse tema, o que aponta a necessidade de fóruns de debates que possam estimular a produção de estudos nessa vertente, devido ao fato de o mercado de trabalho informal ser uma realidade próxima da sociedade.

Tabela 7

Produção acadêmica dos autores

\begin{tabular}{|c|c|c|}
\hline Autores dos artigos & Número de artigos & Descrição da publicação \\
\hline Alexandre de Pádua Carrieri & \multirow{3}{*}{3} & Cadernos EBAPE.BR (2008) \\
\hline Carolina Machado S. de A. Maranhão & & RAP (2009) \\
\hline Ivana Benevides Dutra Murta & & RGO (2009) \\
\hline $\begin{array}{l}\text { Antonio Kremer } \\
\text { José Henrique de Faria }\end{array}$ & 1 & RAUSP (2005) \\
\hline $\begin{array}{l}\text { Ricardo Laino Ribeiro } \\
\text { Maria Scarlet Do Carmo }\end{array}$ & 1 & RGES (2013) \\
\hline $\begin{array}{c}\text { Deise Luiza da Silva Ferraz } \\
\text { João Menna-Barreto }\end{array}$ & 1 & ENEO (2010) \\
\hline $\begin{array}{c}\text { Thales Batista de Lima } \\
\text { Keliane de Oliveira Cavalcante } \\
\text { Márcia da Silva Costa }\end{array}$ & 1 & ENGPR (2011) \\
\hline $\begin{array}{c}\text { Sávio Túlio de Queiroz Oliveira } \\
\text { José Carneiro da Cunha Oliveira Neto } \\
\text { André Luis Marques Serrano }\end{array}$ & 1 & ENANPAD (2011) \\
\hline
\end{tabular}

Fonte: Elaborada pelos autores.

Quanto à formação dos autores dos artigos, o Quadro 2 detalha sua formação profissional à época da publicação do artigo no evento ou no periódico, bem como sua atuação profissional atualmente. Essa busca foi feita com base nos dados fornecidos na Plataforma Lattes e nas informações dos periódicos. 


\section{Quadro 2}

\section{Formação e atuação profissional dos autores}

\begin{tabular}{|c|c|c|}
\hline Autor dos artigos & $\begin{array}{l}\text { Formação profissional no período da pesquisa } \\
\qquad(2004 \text { a 2013) }\end{array}$ & Formação profissional atual* \\
\hline Alexandre de Pádua Carrieri & $\begin{array}{c}\text { Doutor em Administração, professor e } \\
\text { pesquisador da UFMG. }\end{array}$ & Professor titular da UFMG \\
\hline Carolina M. S. A. Maranhão & Mestre em Administração. & $\begin{array}{c}\text { Doutora em Administração pela UFMG. } \\
\text { Professora efetiva da UFOP. }\end{array}$ \\
\hline Ivana Benevides Dutra Murta & Graduada em Turismo & Mestre em Geografia pela UFMG \\
\hline Milena C. N. Mendonça & $\begin{array}{l}\text { Estudante de graduação em Administração } \\
\text { pela FACE/UFMG }\end{array}$ & Não identificado. \\
\hline Alfredo R. Leite da Silva & $\begin{array}{l}\text { Doutor em Administração e professor da } \\
\text { Fucape. }\end{array}$ & Professor efetivo da UFES. \\
\hline Mariana M. P. de Souza & Graduada em Turismo. & $\begin{array}{c}\text { Doutorado em andamento em } \\
\text { Administração na UFMG e professora } \\
\text { efetiva da UFV. }\end{array}$ \\
\hline Antonio Kremer & Mestre em Administração na UFPR. & Não identificado. \\
\hline José Henrique de Faria & $\begin{array}{c}\text { Doutor em Administração pela USP e pós- } \\
\text { doutor pela University of Michigan. Professor } \\
\text { titular da UFPR. }\end{array}$ & Professor da UFPR. \\
\hline Ricardo Laino Ribeiro & Mestre em Administração pela Unigranrio. & $\begin{array}{c}\text { Professor substituto na UERJ; } \\
\text { Coordenador e Docente do Curso de } \\
\text { Graduação em Nutrição da UNIGRANRIO. }\end{array}$ \\
\hline Maria Scarlet do Carmo & Doutorado em Administração pela FGV. & FGV Projetos. \\
\hline Deise Luiza da Silva Ferraz & $\begin{array}{l}\text { Doutora em Administração pela UFRGS. } \\
\text { Professora substituta nessa instituição. }\end{array}$ & Professora efetiva da UFMG. \\
\hline João Menna-Barreto & Graduado em Ciências Sociais na UnB. & $\begin{array}{c}\text { Mestrado (sem informação de conclusão) } \\
\text { em Educação pela Unimep. Exerce cargo } \\
\text { administrativo. }\end{array}$ \\
\hline Thales Batista de Lima & $\begin{array}{l}\text { Mestrando em Administração pela UFPB e } \\
\text { professor substituto nessa instituição. }\end{array}$ & $\begin{array}{c}\text { Doutor em Administração pela UFPB e } \\
\text { professor efetivo nessa instituição. }\end{array}$ \\
\hline Keliane de O. Cavalcante & Mestranda em Administração pela UFPB. & Administradora da UFERSA. \\
\hline Márcia da Silva Costa & $\begin{array}{c}\text { Doutora em Sociologia pela IUPERJ e } \\
\text { professora efetiva da UFPB. }\end{array}$ & $\begin{array}{l}\text { Professora efetiva do curso de } \\
\text { Administração da UFPB. }\end{array}$ \\
\hline Sávio Túlio de Q. Oliveira & Bacharel em Administração. & Não identificado. \\
\hline José C. da C. Oliveira Neto & $\begin{array}{l}\text { Doutor em Administração pela UnB e } \\
\text { professor efetivo dessa instituição. }\end{array}$ & $\begin{array}{l}\text { Pós-doutor pela UnB e professor dessa } \\
\text { instituição. }\end{array}$ \\
\hline André Luiz Marques Serrano & Mestrado em Economia UnB. & Professor UnB. \\
\hline
\end{tabular}

Fonte: Elaborada pelos autores.

Nota: *Período de referência: Julho/2015.

Os dois autores sobre os quais não foi possível obter informações, tanto à época da publicação do artigo como atualmente, apresentaram um mesmo artigo no encontro da Anpad em 2011. Por ser de evento, não há informações sobre eles no artigo e não se conseguiu acessar seus currículos na plataforma Lattes. Sobre Milena C. N. Mendonça, as informações estão desatualizadas no seu Lattes, onde há dados avulsos sobre 2005. No caso de Antonio Kremer, considerou-se provável sua atuação como professor na citada universidade pela informação, fornecida no Lattes, ser referente a 2004, sem atualizações posteriores. 
Nota-se que a formação dos autores pesquisados se concentra mais nas regiões Sul-Sudeste, inclusive com destaque para as universidades localizadas no estado de Minas Gerais, o que leva a pensar se há algum grupo que tenha tentado se estruturar por lá com ênfase em trabalhos sobre o tema e suas relações.

Vale a pena averiguar as referências mais mencionadas pelos pesquisadores, até para perceber quais são os autores mais referenciados por eles, considerando-os os mais renomados na área. Para tanto, foram analisadas as referências de cada artigo.

Tabela 8

Autores referenciados mais citados nos artigos

\begin{tabular}{|c|c|}
\hline $\begin{array}{c}\text { Quantidade de } \\
\text { citações }\end{array}$ & Autor referenciado \\
\hline 8 & CACCIAMALI, M. C. \\
\hline 7 & OLIVEIRA, C. A. \\
\hline 7 & RIBEIRO, R. N. \\
\hline 6 & CARRIERI, A. P. \\
\hline 5 & DURÃES, A. \\
\hline 5 & RAMOS, M. \\
\hline 5 & VIANA, V. M. A. \\
\hline 4 & PEREIRA, M. C. \\
\hline 4 & SILVA, L. A. M.. \\
\hline 4 & BASTOS, V. P. \\
\hline
\end{tabular}

Fonte: Elaborada pelos autores.

Fez-se uma quantificação das referências de cada um dos oito artigos. Somado o número de artigos, encontrou-se uma média de 120 referências. Percebeu-se que a convergência nas citações ainda é baixa, levando ao entendimento de que ainda não há autores tão fortes e frequentes na produção acadêmica sobre o assunto em estudo. As referências citadas são esparsas, por vezes de estudos isolados de algum autor em determinado período de tempo ou espaço, sem que aprofundasse seus estudos nessa área afim.

Surpreendentemente, o mais citado tem apenas oito citações. Alguns desses autores não abordam necessariamente o trabaIho informal em sua amplitude, como Carrieri, que tem uma vertente estratégica da prática social, e Ramos, que trata especificamente dos camelôs.

As referências restantes são citadas um ou duas vezes. Muitos dos autores referenciados tratam particularmente de temas correlatos ao tema maior, qual seja, o trabalho informal. Outra lacuna é a ausência nos artigos do uso de referências internacionais fortes que balizem o assunto na produção nacional.

Na Tabela 9, apresentamos os temas específicos que envolvem os artigos pesquisados, pois, apesar do tema amplo do trabalho informal, esses artigos exploram algumas de suas peculiaridades.

Tabela 9

Temas explorados nos artigos

\begin{tabular}{|c|c|}
\hline $\begin{array}{c}\text { Quantidade de } \\
\text { artigos }\end{array}$ & Tema \\
\hline 2 & Espaço simbólico e estratégia como prática social \\
\hline 2 & Condições de trabalho - precarização \\
\hline 2 & Identidade e sentido do trabalho \\
\hline 1 & Economia submersa \\
\hline 1 & Relação entre mercado de trabalho formal e informal \\
\hline
\end{tabular}

Fonte: Elaborada pelos autores 
Foram estabelecidos cinco temas explorados nos artigos, mesclados com o tema do trabalho informal. $\mathrm{O}$ artigo que se desenvolve pelo viés econômico é o único que enfoca a abordagem quantitativa. Os que abarcam as condições de trabalho refletem sua precarização, o desemprego estrutural e a reestruturação produtiva no país. Já os que abordam a identidade e o sentido do trabalho tentam conhecer a vivência de alguns camelôs para compreender seu modo de vida. Outros dois artigos tratam das perspectivas de significados simbólicos atribuídos pelos entrevistados, por exemplo, à relação casa e rua, bem como às mudanças ocorridas em virtude da mudança de ambientes em seu trabalho, quando são reconduzidos aos centros comerciais populares. Ainda há um artigo que apresenta um diálogo teórico sobre a dicotomia trabalho formal e informal.

Desse modo, percebe-se que o trabalho informal é um tema vasto, cuja produção acadêmica em administração ainda pouco avançou significativamente nos últimos dez anos em periódicos de renome no Brasil e nos principais eventos nacionais promovidos pela Anpad. É um tema que requer aprofundamentos e delineamentos, dada a proporção que vem adquirindo não só no país, mas também internacionalmente, em um momento em que países desenvolvidos sofrem com crises econômicas e veem o desemprego aumentar, os trabalhos se tornarem precários, e as pessoas "sem saída" por vezes tomando o rumo do trabalho informal como meio de sobrevivência, o que retroalimenta a cadeia produtiva formal.

\section{CONSIDERAÇÕES FINAIS}

Este trabalho pôde contribuir na elucidação do tema do trabalho informal, mostrando como vem sendo tratado nos últimos dez anos pelas produções científicas do principal evento nacional de administração no país e dos periódicos de maior relevância no âmbito nacional nessa área.

Nesse sentido, os resultados revelam que a abordagem dos artigos tem sido qualitativa e o tipo de pesquisa descritiva, bem como prevalece a análise do discurso entre os métodos de análise. Os autores dos artigos selecionados não produzem em quantidade significativa sobre o trabalho informal, ou seja, ainda são bem dispersos e pontuais os estudos sobre o tema, mesmo entre os próprios autores que o estudam.

A formação dos principais autores apontados por este trabalho se concentra nas regiões Sudeste e Sul do Brasil, ainda de maneira parca, o que indica que os programas de pós-graduação em administração pelo país não demonstram tanto interesse sobre o assunto, ou até mesmo em desenvolver grupos de pesquisa específicos. Assim, torna-se necessária a produção de pesquisas acadêmicas que se aprofundem no tema no campo organizacional, para que se possa compreender melhor os fenômenos que ocorrem nesse meio social.

Percebe-se pouca convergência no uso das referências pelos autores dos artigos analisados. A autora mais citada foi Cacciamali, e os trabalhos dos outros autores, por vezes transversais ao tema, sem fazer uma análise crítica propriamente dita, tendem a promover um debate com temas correlatos. A produção internacional pouco tem sido adotada nesses artigos, o que leva a refletir o porquê do pouco uso de autores estrangeiros pela produção nacional. Da mesma forma, intriga saber se no exterior o olhar sobre o tema pelos estudiosos também é escasso, ainda mais na área de administração.

Vale ressaltar que é bem possível que alguns pesquisadores nacionais em administração publiquem sobre esse assunto em eventos e periódicos de outras áreas por sofrerem empecilhos em sua própria área, por ser esta profundamente influenciada pela ideia do management, o que também faz pensar sobre o porquê da administração ainda tentar desconsiderar, nos dias de hoje, questões latentes como o trabalho informal, resultantes de problemas organizacionais que dizem respeito ao campo organizacional e social, uma realidade da administração além da visão for business.

Enfim, a informalidade sempre esteve presente na sociedade brasileira, e, nas últimas décadas, ganhou espaço, até em razão das mudanças ocorridas em relação à dinâmica vivida pelo campo organizacional, cujas consequências são ampliadas para o entorno do contexto social. A produção científica em administração pode e deve auxiliar na compreensão das configurações adotadas no campo do trabalho informal.

Espera-se que este trabalho possibilite uma transformação nas perspectivas sobre esse assunto e acredita-se que, no momento vivido pela sociedade, seja propício para pesquisadores da área de administração discutir com maior ênfase esse tema, dando atenção aos rumos do trabalho informal e contribuindo, assim, para o desenvolvimento organizacional e social. 


\section{REFERÊNCIAS}

ABONIZIO, G. P. Informalidade e impactos sociais: questões a partir de um levantamento bibliográfico. In: SEMINÁRIO DO TRABALHO, 7., 2010, Marília. Anais eletrônicos... Marília: UNESP, 2010. Disponível em: <http://www.estudosdotrabalho.org/anais-vii-7-seminario-trabalho-ret-2010/gustavo_pereira_informalidade_e_impactos_ sociais_questoes_a_partir_de_um_levantamento_bilbiografico. pdf>. Acesso em: 9 dez. 2015.

ANTUNES, R. Os sentidos do trabalho: ensaio sobre a afirmação e negação do trabalho. São Paulo: Boitempo, 2000.

BARBOSA, A. F. O conceito de trabalho informal, sua evolução histórica e o potencial analítico atual: para não jogar a criança fora junto com a água do banho. In: OLIVEIRA, R. V.; GOMES, D.; TARGINO, I. (Org.). Marchas e contramarchas da informalidade do trabalho: das origens às novas abordagens. João Pessoa: Editora da UFPB, 2011. 105-159 p.

CACCIAMALI, M. C. Setor informal urbano e formas de participação na produção. $172 \mathrm{f}$. Tese (Doutorado em Economia) - Faculdade de Economia, Administração e Contabilidade, Universidade de São Paulo, São Paulo, 1983.

COSTA, M. S. Despotismo de mercado: medo do desemprego e relações de trabalho. João Pessoa: Editora da UFPB, 2006. 246 p.

COSTA, M. S. Relações de trabalho e os regimes contemporâneos de emprego na Espanha e no Brasil: um breve paralelo. Organizações \& Sociedade, v. 17 , n. 54, p. 499-525, 2010a.

COSTA, M. S. Trabalho informal: um problema estrutural básico no entendimento das desigualdades na sociedade brasileira. Caderno CRH, v. 23, n. 58, p. 171-190, 2010b.

DELFINO, I. A. L.; SILVA, A. B.; ROHDE, L. R. A produção acadêmica sobre liderança no Brasil: uma análise bibliométrica dos artigos publicados em eventos e periódicos entre 1995 e 2009. In: ENCONTRO DA ANPAD, 34., 2010, Rio de Janeiro. Anais eletrônicos... Rio de Janeiro: ANPAD, 2010. Disponível em: < http://www. anpad.org.br/admin/pdf/gpr2749.pdf>. Acesso em: 15 dez. 2015.

DEPARTAMENTO INTERSINDICAL DE ESTATÍSTICA E ESTUDOS SOCIOECONÔMICOS - DIEESE. Encargos sociais no Brasil: conceitos, magnitude e reflexos no emprego. Pesquisa n. 12. São Paulo: Dieese, 1997.

FERRAZ, D. L. S.; MENNA-BARRETO, J. “Manifesto pelo Fim da Exclusão": por uma análise da simbiose entre mercado de trabalho formal e mercado de trabalho informal. In: ENCONTRO DE ESTUDOS ORGANIZACIONAIS DA ANPAD, 6., 2010, Florianópolis. Anais eletrônicos... Florianópolis: ANPAD, 2010. Disponível em: <http:// www.anpad.org.br/diversos/trabalhos/EnEO/eneo_2010/2010_ ENEO409.pdf>. Acesso em: 9 dez. 2015.
INSTITUTO BRASILEIRO DE GEOGRAFIA E ESTATÍSTICA - IBGE. Economia informal urbana. Rio de Janeiro: IBGE, 2003. Disponível em: <http://www.ibge.gov.br/home/estatistica/economia/ ecinf/2003/ecinf2003.pdf>. Acesso em: 15 dez. 2015.

KITCHENHAM, B. et al. Systematic literature reviews in software engineering: a tertiary study. Information \& Software Technology, v. 52, n. 8, p. 792-805, 2010.

KREMER, A.; FARIA, J. H. Reestruturação produtiva e precarização do trabalho: o mundo do trabalho em transformação. Revista de Administração da Universidade de São Paulo, v. 40, n. 3, p. 266279, 2005.

LEITE, M. P. O trabalho no Brasil dos anos 2000: duas faces de um mesmo processo. In: OLIVEIRA, R. V.; GOMES, D.; TARGINO, I. (Org.). Marchas e contramarchas da informalidade do trabalho: das origens às novas abordagens. João Pessoa: Editora da UFPB, 2011. 29-64 p.

LIMA, T. B.; CAVALCANTE, K. O.; COSTA, M. S. Informalidade: escoIha ou falta de opção? Um estudo no Mercado Terceirão de João Pessoa/PB. In: ENCONTRO DE GESTÃO DE PESSOAS E RELAÇÕES DE TRABALHO, 3., 2011, João Pessoa. Anais eletrônicos... João Pessoa: ANPAD, 2011. Disponível em: <http://www.anpad.org. br/diversos/trabalhos/EnGPR/engpr_2011/2011_ENGPR110.pdf>. Acesso em: 9 dez. 2015.

MATTOSO, J. Emprego e concorrência desregulada: incertezas e desafios. In: OLIVEIRA, C. A.; MATTOSO, J. (Org.). Crise e trabalho no Brasil: modernidade ou volta ao passado. 2. ed. Campinas, SP: Scritta, 1997. 13-31 p.

MÉSZÁROS, I. Desemprego e precarização: um grande desafio para a esquerda. In: ANTUNES, R. (Org.). Riqueza e miséria do trabalho no Brasil. São Paulo: Boitempo, 2006. 27-44 p.

OLIVEIRA, F. Crítica à razão dualista: o ornitorrinco. São Paulo: Boitempo, 2005.

SASAKI, M. A. Trabalho informal: escolha ou escassez de empregos? Estudo sobre o perfil dos trabalhadores por conta própria. 2009. 144f. Dissertação (Mestrado em Psicologia Social, do Trabalho e das Organizações) - Universidade de Brasília, Brasília, 2009.

SILVA, L. M. Mercado de trabalho ontem e hoje: informalidade e empregabilidade como categorias de entendimento. In: SANTANA, M. A.; RAMALHO, J. R. (Org.). Além da fábrica: sindicatos, trabalhadores e a nova questão social. São Paulo: Boitempo, 2003. 140-178 p.

SOARES, M. A. T. Trabalho informal: da funcionalidade à subsunção ao capital. Vitória da Conquista, BA: Editora da UESB, 2008.

Thales Batista de Lima

Doutor em Administração pela Universidade Federal da Paraíba (UFPB); Professor Adjunto na UFPB. E-mail: thalesufpb@gmail.com.br

Márcia da Silva Costa

Doutora em Sociologia pelo Instituto Universitário de Pesquisas do Rio de Janeiro (IUPERJ); Professora Adjunta na UFPB. E-mail: marciakosta@ hotmail.com 